\title{
EFFECT OF DATE FRUIT (PHOENIX DACTYLIFERA L.) EXTRACT ON TNF $\alpha$ LEVELS AND BRAIN WEIGHT OF ALZHEIMER'S MODEL RATS
}

\author{
Elita Marintan ${ }^{1}$, Brian Wasita $^{2}$, Adi Magna ${ }^{3}$ \\ Correspondence: brianwasita@yahoo.com \\ ${ }^{I}$ Nutrition Science Study Program, Faculty of Postgraduate, Universitas Sebelas Maret, Surakarta, Indonesia \\ ${ }^{2}$ Medical Study Program, Faculty of Medicine, Universitas Sebelas Maret, Surakarta, Indonesia \\ ${ }^{3}$ Animal Science Department, Faculty of Agriculture, Universitas Sebelas Maret, Surakarta, Indonesia
}

Article History:

Received: May 29, 2021

Accepted: September 27, 2021

Published: January 1, 2022

\section{Cite this as:}

Marintan E, Wasita B, Magna A.

Effect of date fruit (phoenix

dactylifera l.) Extract on tinfa

levels and brain weight of

alzheimer's model rats. Malang

Neurology Journal; 2022.8:25-

29. DOI:

http://dx.doi.org/10.21776/ub.mnj .2022.008.01.6

\section{ABSTRACT}

Background: Alzheimer's disease (AD) is a neurodegenerative disorder marked by brain inflammation resulted in structural damage and brain dysfunction. Tumor necrosis factor $\alpha$ (TNF $\alpha)$ is a cytokine that plays an important role in inflammation. Dates fruit may help to fight oxidative stress and inflammation in the brain.

Objective: To determine the effect of date fruit extracts on blood TNF $\alpha$ levels and brain weight of alzheimer's model rats.

Methods: This research is a laboratory experimental study by post-test only with control group design using alzheimer model rats. This study used 6 treatment groups with simple randomization. Each treatment group was represented by 8 Sprague Dawley rats. The normal control group (KN) was not induced by Hcy and was not given date palm extract, the negative control group (K-) was the Alzheimer's experimental rats which was not given the date palm extract, the positive group was the Alzheimer's experimental rats which was given the Donepezil $(\mathrm{K}+)$. Groups P1, P2, P3 were Alzheimer's experimental rats that were given date palm extract at a dose of $200,400,800 \mathrm{mg} / \mathrm{kgBW}$ / day. The effect of date palm extract dosage on TNFa levels and brain weight were analyzed using the One Way Anova test followed by Tukey's post hoc test.

Results: The difference in TNF $\alpha$ levels between groups showed a significant difference $(\mathrm{p}=0.00)$. Meanwhile there was no significant difference in brain weight among all groups ( $p>0,05)$.

Conclusion: Date palm extract at doses of 200, 400, $800 \mathrm{mg} / \mathrm{kgBW}$ can decrease blood TNF $\alpha$ levels of Alzheimer's model rats.

Keywords: Alzheimer's, TNF $\alpha$, date palm extract, brain weight, inflammation

\section{Introduction}

Alzheimer's disease (AD) is one of neurodegenerative disorders which cause dementia all over the world and still it was most common health problems in old people. ${ }^{1}$ People with Alzheimer's dementia has decreased cognitive development according to its pathophysiological condition. $^{2}$. In accordance with the increase of life expectancy in various countries, it is estimated four times higher $\mathrm{AD}$ cases by 2050 due to lack of medical approaches to prevent the disease. ${ }^{1}$

The inflammatory process is the key in the pathology of Alzheimer's disease. ${ }^{3}$ The neuropathological features of this disease are amyloid plaques and neurofibrillary tangles (NFT), which highly precipitated in the brain. ${ }^{4}$ This neuropathology is closely related to chronic inflammation and neuronal disturbance. Proinflammatory cytokines, such as interleukin (IL) $-1 \beta$, IL-6 and tumor necrosis factor (TNF- $\alpha$ ), have been implicated in the neuritic plaque ordering event in AD. ${ }^{5,6}$ Recent research has shown that neuroinflammatory-mediated cytokines are major contributor to the development of $\mathrm{AD}$, and evidence suggests that inflammation promotes the pathological processes leading to AD. ${ }^{7}$ Studies report that levels of IL$1 \beta$, IL- 6 and TNF- $\alpha$ are elevated in the brain of people who had exposed to AD. These cytokines secreted proteins which turn into senile plaque. In addition, a synergistic effect can also occur between these cytokines as $\beta$-amyloid which increases the production of TNF- $\alpha$ and reactive nitrogen species which are also toxic to neurons. ${ }^{8}$ Proinflammatory cytokines can accelerate the process of neurodegeneration and storage of brain damage. The brain atrophy is the widening of the sulcus and ventricles and the thinning of the gyrus. Patients with $\mathrm{AD}$ experience a decrease in brain weight about 100-200 grams. ${ }^{9}$

In traditional medicine, plant extracts have various medicinal benefits, and have been used to treat various diseases ${ }^{10}$. Safe, effective, and affordable alternative approaches are needed to control disease progression. Natural products are good medicine because they are cheap and easily accessed without complications. ${ }^{11}$ Dates fruit (Phoenix dactylifera L.) is an historical plant which had been innovated as in traditional medicine for treating many diseases. Dates and their constituents act as powerful 
antioxidants and anti-inflammatory, therefore it may provide alternative therapies for various diseases. ${ }^{12}$ Many studies have investigated the beneficial effects of dates on neurological diseases such as Alzheimer's disease (AD), Parkinson's disease (PD), Huntington's disease (HD) and amyotrophic lateral sclerosis (ALS). ${ }^{13,22}$ Among these diseases, $\mathrm{AD}$ is one of the progressive diseases. It is a neurodegenerative disorder that is the main cause of dementia, and characterized by cognitive and memory impairments. Dates contain flavonoid compounds that are able to cross the blood brain barrier which makes flavonoids possible prevent neurodegenerative diseases. ${ }^{14}$

Several studies have shown that flavonoid derivatives namely polyphenols have attenuated nerve cell death caused by oxidative stress. Other studies have shown that antioxidants supplementation can delay the progression of AD. Recent research has reported that dates fruit (Phoenix dactylifera) was a good active source with good ability to reduce free radicals. ${ }^{12,15}$

Previous studies have shown that polyphenols have significant anti-inflammatory effects in vivo and in vitro, both as antioxidants and modulators in the inflammatory redox signaling pathway. ${ }^{16}$ Many polyphenolic flavonoids have been reported to inhibit the expression of proinflammatory cytokines. Quercetin and kaempferol have been shown to inhibit the production of TNF- $\alpha$ and also IL6 during inflammation. ${ }^{17}$

The purpose of this study was to investigate the effect of date palm extract on TNF $\alpha$ levels and brain weight in Alzheimer's model rats.

\section{Methods}

\section{Research Design}

This study was conducted at the Laboratory of Center for Food and Nutrition Studies (PSPG), Gajah Mada University, Yogyakarta. This was a laboratory experimental study with post test only with control group design. The subjects selected in this study were 48 male Sprague Dawley rats, aged 8-10 weeks. Alzheimer's model rats were conditioned by homocysteine induction of $400 \mu \mathrm{g} / \mathrm{kg} /$ day for 28 days through the caudal vein. Subjects were put into 6 groups, namely the KN (normal), K- (Alzheimer's not given date palm extract), $\mathrm{K}+$ (Alzheimer's + Donepezil $1 \mathrm{mg} / \mathrm{kg} / \mathrm{day}), \mathrm{P} 1$ (Alzheimer's + date palm extracts 200 $\mathrm{mg} / \mathrm{kgBW}$ ). , P2 (Alzheimer's + date palm extract $400 \mathrm{mg}$ / kgBW), P3 (Alzheimer's + date palm extract $800 \mathrm{mg} /$ $\mathrm{kgBW}$ ). Date fruit extract was given for 21 and 28 days in a round. The day after the intervention, $1 \mathrm{ml}$ of medial canthus sinus orbitalis was taken, then the rats were euthanized by ether inhalation. All research procedures were carried out with the approval and supervision of the Veterinary Ethics Committee of the Faculty of Medicine UNS No: 106 / UN27.06.6.1 / KEPK / EC / 2020.

\section{Dates Fruit Ethanol Extract}

Dates fruit ethanol extract was made at PSPG UGM Yogyakarta. The dates used are the Ajwa dates from Madinah. Extraction process using maceration method. The solvent used is alcohol (ethanol). Extraction was carried out by manually separating the dates (Phoenix dactylifera) from the seeds and drying them at room temperature. Dates fruit were cut into small pieces then heated in the oven at $80^{\circ} \mathrm{C}$ for \pm 48 hours. After the heating process, they were grinded into a powder using a stainless-steel blender. Date fruit powder was macerated using ethanol for 24 hours (1:2) during the stirring process. The output of the maceration were filtered using Whattman filter paper. Then the filtrate was evaporated with a rotary evaporator to obtain a thick extract of the flesh of the ajwa dates. Dates extracts are made with the aim that active compounds such as flavonoids and polyphenols contained in dates can be attracted to the solvent. ${ }^{18}$

\section{Rats' Brain Weight Determination}

The initial whole rat brains were immediately removed from the skull and weighed using digital scales. The brain weight was recorded in wet brain weight $(\mathrm{g})$.

\section{Examination of TNFa Serum levels using the ELISA method}

The blood was collected and centrifuged for $10 \mathrm{~min}$ at $10,000 \mathrm{rpm}$. The serum was collected and was used to determine TNF $\alpha$. The ELISA was performed according to the manufacturer's instruction. The intensity of the color in the 96-well plate was measured at $450 \mathrm{~nm}$ using a plate reader.

\section{Statistical Analysis}

$\mathrm{TNF} \alpha$ levels data were obtained and expressed in terms of the mean standard deviation (SD). Data analysis was carried out by using the One Way Anova test to determine the difference in the average levels of TNF $\alpha$ and the treatment group followed by Tukey HSD pos hoc test. All data were analyzed with a confidence interval of $95 \%$ (p $<0.05)$ using SPSS 21 software.

\section{Results}

\section{TNFa Level Evaluation}

One way ANOVA test results showed a significant effect of date palm extract on the mean TNFa levels in Alzheimer's model rats at 21 and 28 days of administration with the same value $\mathrm{p}=0.001(\mathrm{p}<0.05)$ (Table 1$)$.

Further analysis using Tukey's HSD test on each group were performed to show TNF $\alpha$ levels on days 21 and 28 (see Table 1 and Figure 1). Comparison of TNF $\alpha$ levels on day 21 showed a significant difference between the $\mathrm{KN}$ and $\mathrm{K}$ - groups, this was indicated that homocysteine induction for 21 days increased TNF $\alpha$ levels. Significant differences were also shown on group receiving date palm extracts of 200, 400 and $800 \mathrm{mg} / \mathrm{kgbb}$ (P1,P2,P3), which decreased $\mathrm{TNF} \alpha$ levels respectively. However, there wasn't any different in TNF $\alpha$ levels between $\mathrm{KN}$ and $\mathrm{K}+$ groups. This was indicated that the administration of Donepezil $(\mathrm{K}+$ group) inhibited the increase of TNF $\alpha$ level as KN group showed. $\mathrm{K}+$ group and $\mathrm{P} 3$ group did not show a significant difference in TNF $\alpha$ levels. Date palm extract received in the P3 group had equal effect with the $\mathrm{K}+$ group.

Comparison of TNF $\alpha$ levels on day 28 between the $\mathrm{KN}$ and $\mathrm{K}$ - groups showed a significant difference, it was indicated that homocysteine induction for 28 days increased $\mathrm{TNF} \alpha$ levels. Significant differences were also shown in group P1,P2,P3 (received date palm extracts of 200, 400 and 800 $\mathrm{mg} / \mathrm{kgbb}$ respectively), with decreased levels of TNF $\alpha$ sequentially. However, there wasn't any different in TNF $\alpha$ levels between $\mathrm{KN}$ and $\mathrm{K}+$ groups. This was indicated that 
the administration of Donepezil ( $\mathrm{K}+$ group) inhibited the increase of TNF $\alpha$ level as $\mathrm{KN}$ group showed. $\mathrm{K}+$ group and $\mathrm{P} 3$ group did not show a significant difference in TNFa levels. Date palm extract received in the P3 group had equal effect with the $\mathrm{K}+$ group.

Table 1. TNF $\alpha$ Serum Levels

\begin{tabular}{lll}
\hline Treatment Group & Day 21 $(\mathbf{p g} / \mathbf{m l})$ & Day28 $(\mathbf{p g} / \mathbf{m l})$ \\
\hline KN (normal control) & $6,87 \pm 0,40^{\text {af }}$ & $6,82 \pm 0,68^{\mathrm{a}}$ \\
K- (alzheimer control) & $22,67 \pm 1,10^{\mathrm{b}}$ & $23,06 \pm 0.93^{\mathrm{b}}$ \\
K+ (donepezil 1mg/kgBW/day) & $8,97 \pm 0,58^{\mathrm{ac}}$ & $8,62 \pm 0,82^{\mathrm{ac}}$ \\
P1 (EEBK 200 mg/kgBW) & $19,49 \pm 1,42^{\mathrm{d}}$ & $18,56 \pm 0,42^{\mathrm{d}}$ \\
P2 (EEBK 400 mg/kgBW) & $13,32 \pm 1,67^{\mathrm{e}}$ & $13,47 \pm 0,75^{\mathrm{e}}$ \\
P3 (EEBK 800 $\mathrm{mg} / \mathrm{kgBW})$ & $9,41 \pm 0,75^{\mathrm{cf}}$ & $9,36 \pm 0.88^{\mathrm{c}}$ \\
\hline$p$ & 0,000 & 0,000 \\
\hline
\end{tabular}

EEBK: date palm ethanol extract; values are expressed as mean \pm $\mathrm{SD}, \mathrm{n}=4$

a,b,c,d,e,f Different notations in the same column indicate significant differences $(p<0,05)$.

Data were analyzed by one way ANOVA, followed by the Tukey HSD post-hoc test.

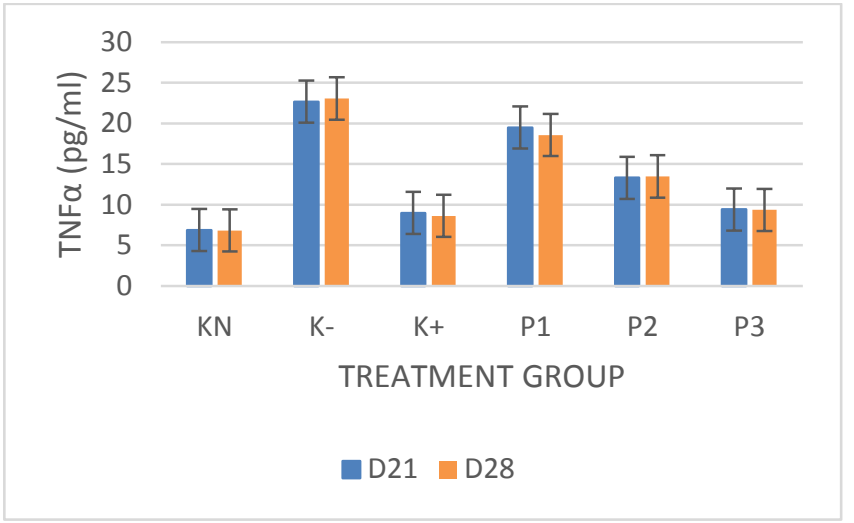

Figure 1. Effect of date fruit extract administration on TNF $\alpha$ levels at 21 and 28 days.

\section{Brain Weight Evaluation}

The brain weight of all subject didn't showed any significance either on day 21 of date fruit extract administration $(p=0.694)$ or on day 28 of date fruit extract administration $(p=0.564)$. Data were displayed as mean \pm standard deviation in each group (Table 2). There were no difference in brain weight between groups. Figure 2 shows that the negative control treatment has lower mean concentration compared to positive control group and normal control group. P1, P2, P3 groups have lower mean compared to the negative control group. There were no increase in brain weight on P1, P2, and P3 groups.

Table 2. Brain Weight

\begin{tabular}{lcc}
\hline Treatment Group & Day 21 $(\mathbf{g})$ & Day 28 $(\mathbf{g})$ \\
\hline $\mathrm{KN}$ (normal control) & $1,86 \pm 0,28$ & $1,71 \pm 0,11$ \\
$\mathrm{~K}$ - (alzheimer control) & $1,70 \pm 0,26$ & $1,73 \pm 0,52$ \\
$\mathrm{~K}+($ donepezil & $1,81 \pm 0,05$ & $1,78 \pm 0,18$ \\
$1 \mathrm{mg} / \mathrm{kgBW} /$ day) & & \\
P1 (EEBK 200 mg/kgBW) & $1,72 \pm 0,14$ & $1,67 \pm 0,22$ \\
P2 (EEBK 400 mg/kgBW) & $1,69 \pm 0,16$ & $1,55 \pm 0,08$ \\
P3 (EEBK $800 \mathrm{mg} / \mathrm{kgBW})$ & $1,68 \pm 0,07$ & $1,71 \pm 0,29$ \\
\hline$p$ & 0,694 & 0,564 \\
\hline
\end{tabular}

EEBK: date palm ethanol extract; values are expressed as mean \pm $\mathrm{SD}, \mathrm{n}=4$

Data were analyzed by one way ANOVA, followed by the Tukey HSD post-hoc test.

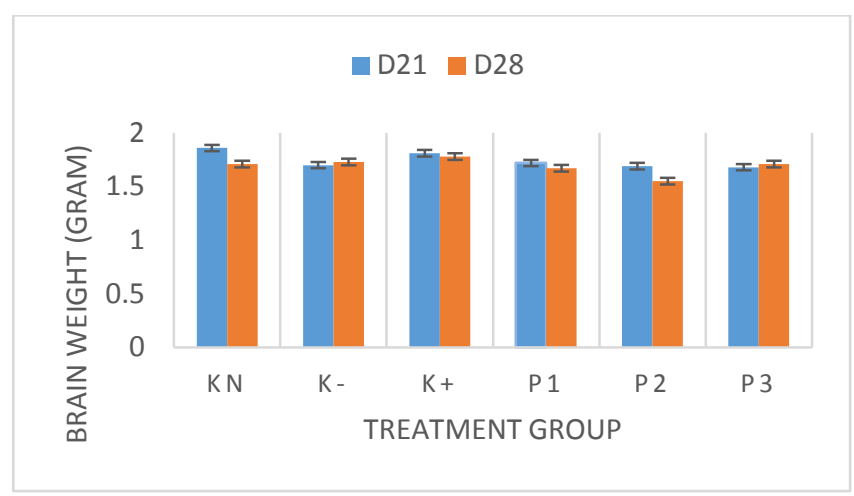

Figure 2. Effect of date fruit extract administration on brain weight at 21 and 28 days.

\section{Discussion}

Inflammatory process involving cytokines played a very significant role in the pathology of Alzheimer's disease. Tumor necrosis factor $\alpha(\mathrm{TNF} \alpha)$ is the most involved cytokine in the cytokine cascade during the inflammatory response. $^{8}$

Inflammation is an normal defensive respon of human body in conditions such as infections, toxic chemicals, allergens and other stimuli. ${ }^{13}$ Inflammatory process imbalance will provoke the development of various diseases. Reactive oxygen species (ROS) and pro-inflammatory cytokines have been reported to have correlation with Alzheimer's disease. $^{8}$ It has been suggested that amyloid beta accumulation in Alzheimer's disease had caused the increased of free radicals. This may induce oxidative stress by increasing oxidative damage to biomolecules and increase cytokine proinflammatory production. ${ }^{3}$

Dates fruit has been reported for its anti-inflammatory property. ${ }^{19}$ Recent studies have found that phenolic compounds and flavonoids in dates fruit has antiinflammatory activity. ${ }^{20}$ Ajwa dates fruit inhibit the expression of pro-inflammatory cytokines (IL-6, IL-10 and TNF- $\alpha)^{21}$ Date fruit's anti-inflammatory effect was marked by its polyphenol compounds which act as antioxidant in order to counteract free radicals and prevent unwanted biochemical reactions during the inflammatory process. ${ }^{19}$

In this study, TNF $\alpha$ levels in K-group showed the highest level compared to other groups. High levels of $\mathrm{TNF} \alpha$ indicated an inflammatory process in Alzheimer's disease. In the date fruit extract treatment group at a dose of 200, $400,800 \mathrm{mg} / \mathrm{kgb}$, the TNF $\alpha$ level decreased significantly. Instead of absence previous similar studies, these results are consistent with previous research by Essa et al (2015) which reported long-term supplement use (15 months) of dates fruit supplementation significantly decreased proinflammatory cytokines such as IL-1 $\beta$, IL-2, IL-3, IL-4, IL-5, IL-6, IL-9, IL-10, TNF- $\alpha$ activity and eotaxin in transgenic AppSw2576 mice model of Alzheimer's disease.

Inflammation process occurred in Alzheimer patients may cause brain injury and neurodegenaration, and finally leading to brain atrophy. Pathological changes in Alzheimer's disease was characterized by the presence of 
immunoreactive senile amyloid plaques and tau immunoreactive neurofibrillary tangles in the brain. ${ }^{23}$ These were associated with decreased nerve density identified as sulcus dilation and gyri shrinkage, with significantly reduced brain weight. Date fruit extract administration on Alzheimer's model rats are expected to have an effect on brain weight gain. ${ }^{9}$

In this study, brain weight results analysis of Alzheimer's model rats receiving date palm extract showed no significance among groups. Administration of date palm extract with three different doses did not give any increasing effect on brain weight in Alzheimer's disease. Due to absence of previous similar study, further study with longer observation may be needed.

\section{Conclusion}

Dates' fruit extract contains antioxidants which work as an anti-inflammatory agent and decrease TNF $\alpha$ levels so that it can prevent the development of Alzheimer's disease in rat model. Dates fruit extract $800 \mathrm{mg} / \mathrm{kg} \mathrm{BW} /$ day are the most effective dose in reducing TNF $\alpha$ level, therefore it may be used as an alternative in preventing inflammatory conditions in Alzheimer's disease in the future.

\section{Conflict of Interest}

The authors mention that there is no conflict of interest

\section{Acknowledgement}

The authors thank to Universitas Sebelas Maret for facilitating this reserach.

\section{References}

1. Alzheimer's Association. 2016 Alzheimer's disease facts and figures. Alzheimers Dement; 2016. 12:459509. DOI: 10.1016/j.jalz.2016.03.001

2. Pariama AP, Ranimpi YY, Setiawan A. Subjective well-being and healthy behavior of elderly with dementia alzheimer's (a phenomenological study). Malang Neurology Journal; 2020.6:82- 87.

DOI: 10.21776/ub.mnj.2020.006.02.7

3. Serrano-Pozo A, Mielke ML, Gómez-Isla T, Betensky RA, Growdon JH, Frosch MP. Reactive glia not only associates with plaques but also parallels tangles in Alzheimer's disease. Am J Pathol; 2011. 179:1373-84 . DOI: 10.1016/j.ajpath.2011.05.047

4. Citron M. Alzheimer's disease: Strategies for disease modification. Nat Rev Drug Discov; 2010. 9:387-398. DOI: $10.1038 / \mathrm{nrd} 2896$

5. Miron VE, Boyd A, Zhao JW, Yuen TJ, Ruckh JM, Shadrach JL, et al. M2 microglia and macrophages drive oligodendrocyte differentiation during CNS remyelination. Nat Neurosci; 2013.16: 1211-8.

DOI: 10.1038/nn.3469

6. Loane DJ, Byrnes KR. Role of microglia in neurotrauma. Neurotherapeutics; 2010.7: 366-77. DOI: 10.1016/j.nurt.2010.07.002

7. McCaulley ME, Grush KA. Alzheimer's disease: Exploring the role of inflammation and implications for treatment. Int J Alzheimers Dis; 2015. 2015:515248. DOI: $10.1155 / 2015 / 515248$

8. Rubio-Perez JM, Morillas-Ruiz JM. A review: Inflammatory process in Alzheimer's disease, role of cytokines. Sci World J; 2012.2012.

DOI: $10.1100 / 2012 / 756357$

9. Budson, AE, Solomon PR. Alzheimer's disease dementia and mild cognitive impairment due to alzheimer's disease. Memory Loss. Alzheimer's Disease, and Dementia; 2016:47-69.

ISBN: 9780323286619

10. Uddin R, Kim HH, Lee J, Park SU. Neuroprotective effects of medicinal plants. EXCLI Journals; 2013. 12:541-545. Avalaible from: ncbi.nlm.nih.gov/pmc/articles/PMC4803005/

11. Ashafa AO, Olunu O. Toxicological evaluation of ethanolic root extract of Morinda lucida (L.) Benth. (Rubiaceae) in male Wistar rats. J Nat Pharm; 2011. 2(2):108-108. Avalaible from: https://www.researchgate.net/publication/232273145_ Toxicological_evaluation_of_ethanolic_root_extract_ of_Morinda_lucida_L_Benth_Rubiaceae_in_male_Wi star_rats

12. AH Rahmani, SM Aly, H Ali, AY Babiker, S. Suikar, and AA Khan. Therapeutic effects of date fruits (Phoenix dactylifera) in the prevention of diseases viamodulation of antiinflammatory, anti-oxidant and anti-tumour activity. Int J Clin Exp Med; 2014. 7(3):483-491.

13. Subash S, Essa MM, Al-Asmi A, Al-Adawi S, Vaishnav R, Guillemin GJ. Effect of dietary supplementation of dates in Alzheimer's disease APPsw/2576 transgenic mice on oxidative stress and antioxidant status. Nutr Neurosci; 2015. 18:281-288. DOI: 10.1179/1476830514Y.0000000134

14. Gao X, Cassidy A, Schwarzschild M, Rimm E,; Ascherio A. Habitual intake of dietary flavonoids and risk of Parkinson disease. Neurology; 2012. 78, 11381145. DOI: 10.1212/WNL.0b013e31824f7fc4

15. Manjeshwar SB, Bantwal RVB, Shaun M K, Harshith PB, Vayalil PK. A review of the chemistry and pharmacology of the date fruits (Phoenix dactylifera L.). Food Research International; 2011.44:1812-22. Avalaible from: https://www.academia.edu/16346659/A_review_of_th e_chemistry_and_pharmacology_of_the_date_fruits_P hoenix_dact

16. Li A-N, Li S, Zhang Y-J, Xu X-R, Chen Y-M, Li HB. Resources and biological activities of natural polyphenols. Nutrients; 2014.6:6020-47. DOI: $10.3390 /$ nu6126020

17. Watson RR, Preedy VR, Zibadi S. Polyphenols in human health and disease: Academic press; 2013. ISBN: 9780123984562

18. Tiwari P, Kumar B, Kaur M, Kaur G and Kaur H. Phytochemical screening and extraction: A review. Internationale Pharmaceutica Sciencia; 2011. 1: 98106. Available from: https://www.semanticscholar.org/paper/Phytochemical -screening-and-Extraction\%3A-A-Review-TiwariKaur/979e9b8ddd64c0251740bd8ff2f65f3c9a1b3408

19. Zhang CR, Aldosari SA, Vidyasagar PS, Nair KM and Nair MG. Antioxidant and anti-inflammatory assays 
confirm bioactive compounds in Ajwa Date fruit. J Agric Food Chem; 2013.61:5834-5840.

DOI: $10.1021 / \mathrm{jf} 401371 \mathrm{v}$

20. Das R, Shinjini M, Kaustab M, Umesh PS, Banerjee ER Anti-oxiflammatory profile of date extracts (phoenix sylvestris). Biom Res Therapy; 2015. 2(6):297-317. Avalaible from: http://www.bmrat.org/index.php/BMRAT/article/view 153

21. Al-Yahya M, Raish M, AlSaid M S, Ahmad A, Mothana RA, Al-Sohaibani M, et al. Ajwa' Dates (Phoenix Dactylifera L.) extract ameliorates isoproterenol-induced cardiomyopathy through downregulation of oxidative, inflammatory and apoptotic molecules in rodent model. Phytomedicine; 2015.23 (11):1240-1248.

DOI: $10.1016 /$ j.phymed.2015.10.019

22. Essa MM, Subash S, Akbar M, Al-Adawi, Guillemin GJ. Long-term dietary supplementation of pomegranates, figs and dates alleviate neuroinflammation in a transgenic mouse model of Alzheimer's disease. PLoS One; 2015. 10:e0120964. DOI: 10.1371/journal.pone.0120964

23. Kumar A, Singh A, Ekavali. A review on Alzheimer's disease pathophysiology and its management: An update. Pharmacol Rep; 2015.67(2):195-203.

DOI: 10.1016/j.pharep.2014.09.004 